\title{
Creative Dialogues across Countries and Culture during COVID-19
}

\author{
创造性艺术探索：新冠疫情中的国际跨文化对话 \\ Steve Harvey ${ }^{1}$, Si Wang ${ }^{2}$, E.C. Kelly ${ }^{3}$, Joan Wittig ${ }^{4}$, Xia Li ${ }^{5}$, \\ Xiaoxi Peng 6 , Tingting Song ${ }^{2}$, Alethea Bordallo ${ }^{1}$ \\ ${ }^{1}$ University of Guam, Guam \\ ${ }^{2}$ Inspirees Institute, China \\ ${ }^{3}$ University of Auckland, New Zealand \\ ${ }^{4}$ Pratt Institute, USA \\ ${ }^{5}$ Beijing Heart Dance Psychological Consulting, China \\ ${ }^{6}$ University of Chongqing, China
}

\begin{abstract}
This article reports on an online collaboration among creative arts therapists (CATs) from the West and East during the emerging worldwide health crisis related to coronavirus. Four women were from China and were in a restrictive quarantine as the crisis was emerging in that country. Three CATs were from Guam, a Pacific island territory of the United States. The other CAT was from New York City. This group met once across several time zones in a ZOOM room. The goal was to develop arts-based communication about their personal subjective experience of the health crisis. Most of the members of the group were new to each other, each other's languages and culture, and to using the Internet as an avenue for spontaneous expressive communication. The overall purpose of the meeting was to reach out to each other during this unusual and tragic time to develop collaborative metaphor making as a way to understand each other's experiences. The group used improvised dance, art, poetry, and fairy tale making. The resulting metaphors suggested a complex combination of the feelings related to both the destructiveness of the health crisis as well as the positive feeling of creative connections among those from different countries and cultures in this dramatic time.
\end{abstract}

Keywords: Creative arts therapy, Dance therapy, Cross-cultural understanding, Response to the health crisis, Coronavirus, COVID-19, drama therapy

\section{摘要}

本文报道了疫情期间东西方创造性艺术治疗师们之间的在线合作。随着疫情所带来的危 机在中国出现，四名中国的创造性艺术治疗师进入了居家隔离中。另外三名创造性艺术 治疗师来自美属太平洋岛屿领土关岛。最后，一名创造性艺术治疗师来自纽约市。这次 活动中，该团体通过ZOOM会议平台跨越多个时区见面，目的是发展关于他们对健康危 机的个人主观经历的基于艺术的交流。团体的大多数成员彼此都是陌生的，对彼此的语 言和文化也不熟悉。我们希望利用互联网作为自发的表达交流的渠道。会议总体的目的 是在这个不寻常且悲惨的时刻联系彼此并共同创造一些意象，以此来理解彼此的经历。 该小组使用即兴舞蹈、艺术、诗歌和神话故事的方法。通过这次交流所产生的多种意象 


\section{表明，弥漫在这个戏剧性的时代的，是一种与健康危机的破坏性以及来自不同国家和文 化的人们之间创造性联系的积极感觉相关的复杂感受。}

关键字 : 创造性艺术治疗，舞蹈治疗，跨文化理解，对健康危机的反应，新冠病毒， COVID-19， 戏剧治疗

\section{Introduction}

In early February 2020, creative arts therapists (CATs) from the East and West developed a collaboration of dance improvisations, art-making, poetry, and fairy tale making to share their personal experiences with the emerging health crisis related to the coronavirus. We assumed that we would collectively create new metaphors that would express our nonverbal experiences that were not easily understandable. Four participants were from China. They were living in forced quarantine and were unable to leave their homes as the crisis was developing in their country. The participants from the West were still living in "normal conditions" at the time of the event. We used the Internet to join each other in real time simultaneously across several time zones. The project grew out of our communications following the recent cancellation of an international conference scheduled to be held in Hangzhou, China, during the first week in March and upcoming webinars. The public conversations in both cultures had not yet included expression of individual subjective experience. During our contacts, we recognized that we had a unique opportunity to reach out and attempt to use our improvisations to develop a deeper communication between our countries. We were hoping to use collaborative art-making to develop more personal and emotionally relevant connections and that our images and themes could help point to important communications among other countries and cultures.

\section{Other Projects that Develop Metaphors over Distance}

Other projects and authors have reported on using the Internet and other forms of communications to develop art-related communications across distance.

The Laban/Bartenieff Institute of Movement Studies has organized a series of dance events across the world to inspire international collaboration related to the preservation of water using the "universal language" of dance. Each year since 2011, this project has invited dancers from many sites around the world to perform and record dance rituals in their country at the same time. These performances are then gathered and presented as a whole on the Internet. In 2019, more than 150 sites participated and submitted video material. The results can be viewed at http:/globalwaterdances.org/.

Wang and Green (2017) reported on using several forms of communications such as Skype, telephone, email, and snail mail in an exchange of art-making and creative writing from different cities in New Zealand about their subjective experiences of being recent migrants in a new country and culture. One author was from the China and the other was from Africa. Although each was living in a different city, they reported being able to develop metaphorical conversations about their complex subjective and personal experiences with each other using the creative arts. 
Harvey, Zhou, Kelly, and Wittig (2018) reported on a project in which participants from China and the United States met in person to create collaborative metaphors related to their subjective experiences of "what it feels like to live in the world today." In this project, participants from the East and West used "physical conversations" based on dance improvisations followed by spontaneous art and poetry responses to co-create metaphors with each about their emotional experience of the contemporary world in a time of political tensions between their countries. The video of their dance inspired expression is available online in their article in CAET.

Wang (2020) responded to her American dance/movement therapy colleagues' question on how they could help the people in China during the epidemic by making a video with her family. In the video, reference was made to the "park dances" practiced by nurses and patients in the mobile cabin hospitals in Wuhan. The video then connects the felt experiences of inhabitants of the hospital and viewers by inviting viewers to learn three park dance steps and to move together (https://www.youtube.com/ watch? $\mathrm{v}=9 \mathrm{wgIGk} 9 \mathrm{wZng}$ ).

In each of these projects, collaborative metaphors were created to share subjective engagement through several arts expressions across a physical distance using a variety of Internet and other connections. Importantly, the aim of each of these projects was to develop a communication that encouraged a sharing of subjective emotional experience through metaphor making as an alternative to usual and verbal/analytic public conversations.

\section{Beginning Structure of the Event}

In this project, eight CATs met in an online ZOOM room at the same time despite the wide international time differences (from New York to Beijing). This was the initial meeting of several of the participants. Three participants were from Guam, a small Pacific island territory of the United States. This group included two experienced CATs and their colleague. They often meet to create improvisations to explore emotional responses to contemporary themes of the Pacific Islands. One other participant was an experienced dance movement therapist from New York City. The four women from China are CATs and are in a peer supervision group. All had agreed to participate as a creative outreach to develop an understanding of each other's subjective experiences as this crisis was developing. The participants from Guam and New York did not speak Mandarin. One CAT from China translated between English and Mandarin, as the other Chinese women spoke limited English. Many of the participants did not know each other prior to the event. All were unfamiliar to each other's improvisation.

The participants used physical storytelling (Harvey \& Kelly, 2016, 2017a,b, 2018) as a basic structure to organize the collaboration. Physical storytelling is a form in which a small group of dancers develop improvisations to verbal narratives to creatively expand the initial material. All the participants then respond to the dance episodes using art and poetry to create a series of multimodal metaphors.

An important part of physical storytelling involves having the person presenting the narrative be a witness to those who create dance improvisations so that the dance 
can reflect and creatively expand the somatic and often unspoken aspects of the material. One of the central parts of this session was having the verbal narrative be presented by someone from one country/culture, while others from another country/ culture developed the improvisation in response to that narrative. This practice of a person verbally expressing a life experience and another responding with movement is viewed as important in facilitating the communication of subjective emotional experience among our diverse group. Another aspect of physical storytelling involves the engagement of those watching as witnesses who use the movement as a stimulus of active imagination to influence their spontaneous art and poetry making following the dance improvisations. A final aspect from physical storytelling is the use of improvisation. We had no set goal of end point at the beginning of this session. We were expecting that the spontaneous metaphor making of this process to lead to an expanded expression of nonverbal aspects of our verbal stories, images that are complex and mostly unknown prior to this co-creative process. These metaphors have been called the story under the story (Harvey \& Kelly, 2016).

In this event, some translations occurred after the improvisations were finished and were not simulations for the most part. The arts-based improvisations served as the main avenue of communication. The dance improvisations were solos to accommodate the limits of using ZOOM.

\section{Use of ZOOM}

The process of using ZOOM was familiar to some of the participants. Two in particular had experience with teaching and supervising groups using this technology. Inspirees Institute is also now using ZOOM to offer a series of webinars to present education around dance movement therapy. Some of the women from China have been students of Inspirees.

For this session, some of the features that were utilized included pinning a mover so that they would be in full screen as the mover was dancing a solo. As each person shared their artwork and writing, one author (E.C.K.) recorded the event, pinned each participant as they shared to again place them as the main speaker of the moment so their artwork could be as visible as possible for participants.

\section{Initial Structure and Goal of Project}

The goal of the project was to use collaborative dance, art, poetry, and imaginative fairy tale making online to create metaphors of our personal experiences during the health crisis to facilitate an understanding of each other. An outline of the goal was provided prior to the beginning of the Internet event. We also needed to find a way to learn how to use the Internet to communicate with each other. This was particularly true with finding a way to move onscreen so others could view the improvisations and how any translations could be done and heard. We found that most of these challenges were addressed by taking time to adjust during the session. We were also new to each as improvisers. 
This situation provided us with the unique challenge of learning about each other and our way of creating together from our diverse backgrounds as well as understanding each other in this crisis. We realized that we are a unique group coming from countries that are typically considered as foreign and in conflict as defined by our political leaders in some ways. Our exchanges of personal improvisations during the actual time of crisis were seen as a valuable avenue to develop co-creatively that would not otherwise develop. We considered our improvisations as an important way for those in the East and West to begin creative dialogue about subjective emotional experiences by using collaborative metaphor making in this unusual and dramatic time. We were aware that tensions were developing among different countries, as we began improvising with each other while real human tragedies were unfolding around those in China with the expectations that similar tragic events would soon emerge throughout much to the world. In this way, we could be considered as representing not only ourselves but as being able to express parts of a very complex worldwide event. Therefore, our improvisational metaphors have the potential to contribute to others in countries as this new global event emerges.

\section{The Session}

The session began with group movement in which group members followed one leader and then passing the leadership among each other. In the next step, each person used a unique movement to introduce themselves with their name and where they were from while the group followed these movement gestures. During the process of these DMT activities, we were able to begin to understand how we could be seen on screen, and more importantly, we began to recognize each other's nonverbal cues to develop a physical attunement with each other.

The CATs from China then verbally presented brief personal images from their life during the quarantine and a member from either Guam or New York responded with a solo movement improvisation. Initially, the teller and the dancer described their experiences, Then, each member of the group was able to respond verbally to what the experience was like. The personal life experiences during the quarantine varied from being unable to bury a pet because of being forced to be inside, viewing the emptiness of the city streets, being apprehensive of getting too close to others, and noticing people on either side of a door as being inside or outside in a physical and subjective sense. These presentations each had the suggestion of strong emotional aspect.

Each of the solo movement improvisations led to expanded physicalized emotional expression. The themes of the verbal responses to witnessing these danced personal stories were feeling satisfied with observing these details from their lives moved by someone else, feeing relieved that the strong feelings in their story were contained in another person's dancing, being able to see new aspects of their story in the dances, and feeling more connected through the verbal/dance expression. The group members from the West reported the dances brought up their sadness associated with the global tragedy of the crisis and for those in China. One group member from the West described how 
dancing about being unable to attend to the death of a pet as told by a woman in China brought up her feeling of being separated from her family during the serious illness of a parent. All group members reported that they experienced connection. The comments indicated that we were communicating important personal emotional experiences with each other.

\section{A Dance of a Personal Story}

The leader of the event suggested that the group move on to the section in which any individual group member be able to present longer personal stories, choose another person to dance their story and then for the group to develop art and poetry responses. The group agreed. A Chinese woman told a story of wishing to escape to the mountains just outside her city to find a quiet place and calmness. She had this wish immediately prior to the outbreak and lockdowns related to the health crisis.

Then, after the quarantine came, she was both unable to go on her trip and she became isolated in her home. Her own summary was that it felt that her room had become the mountain that she had wished to escape to. The first author (S.H.) was conducting this story. He offered the summary of the story as that peace this woman had been seeking changed into isolation. She agreed. This woman then chose the woman from New York to do an improvised solo. After the solo was finished, the group developed art and verbal responses.

Figure 1 presents a series of our pictures and poetry:

\section{Summary Improvisations}

After this dance, we created a summary for our event in which one person improvised a dance while another improvised a fairy tale in response. We did one fairy tale in English with two members from Guam, and two Chinese women created another in Mandarin. These fairy tale dances were created as a summary. Videos 1 and 2 of these improvisations are available in the online version of this article. Figure 2 shows the responses to the fairy tales.

\section{The English Fairy Tale}

During the evening when the darkness falls from the sky The colours from the clouds, sky, and moon come through the trees

And decorate the leaves

This evening the winds came

With little dare devils all under the forest cover

The darkness looking for what to pull up and what to grab

And what to pull out of the ground

The storm intensified and became a typhoon

\section{The Mandarin Fairy Tale (Translated)}

Long, long time ago. The sky and earth is not yet separated. The sky and earth are mixed. Until one day. A very able god-goddess appears. Because of It the whole world 

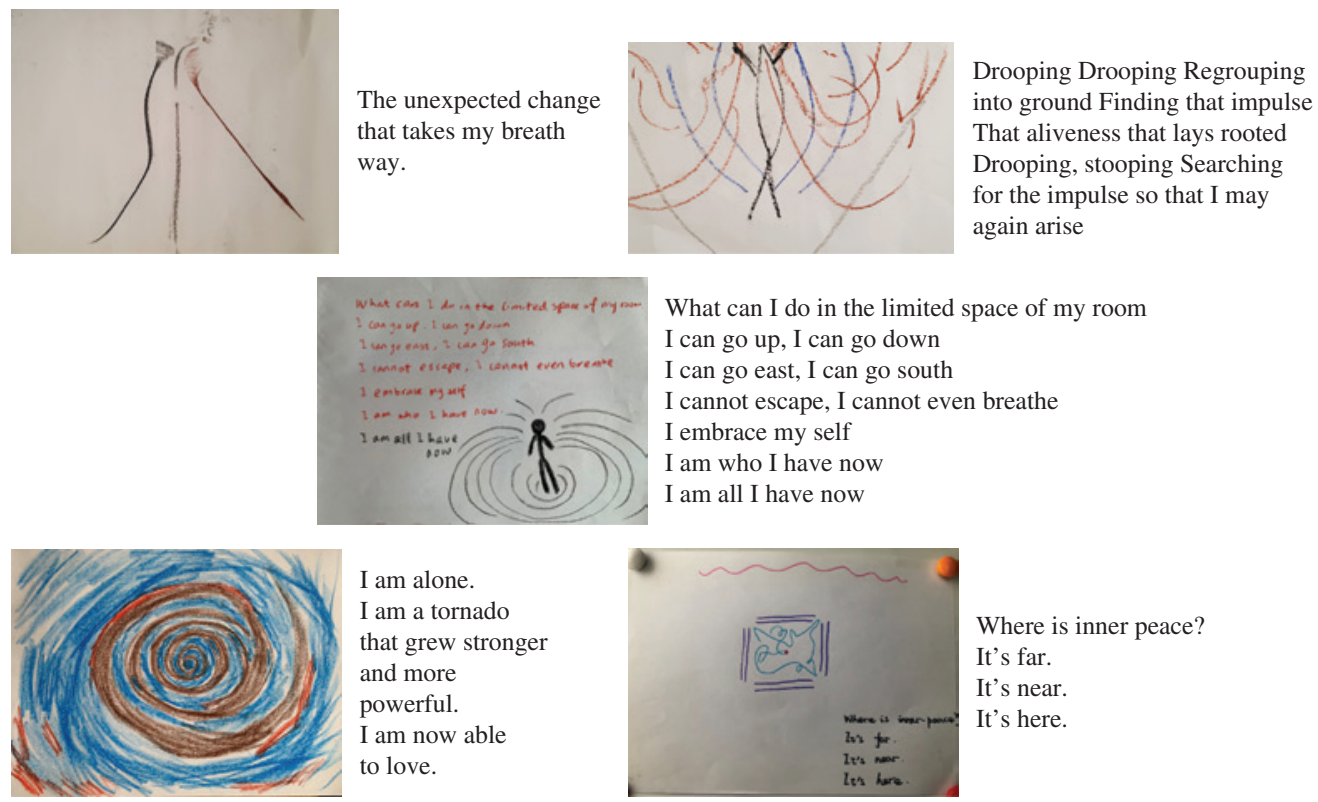

I am alone.

I am a tornado that grew stronger and more powerful. I am now able to love.

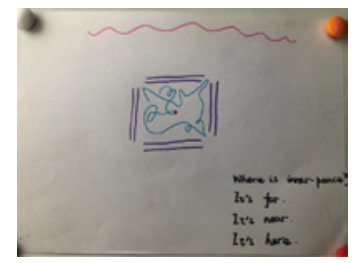

Where is inner peace?

It's far.

It's near.

It's here.

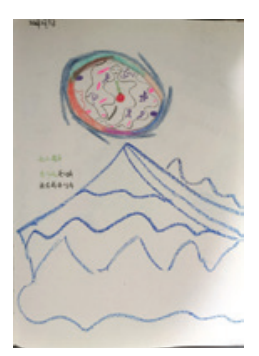

Seeing the mountain far away

Living the mountain close by

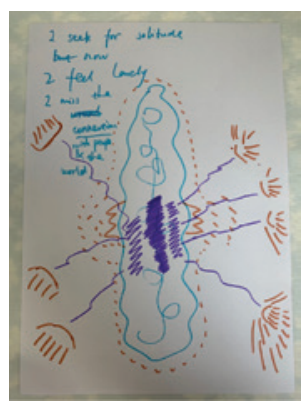

I seek for solitude

But now

I feel lonely

I miss the connection

with people

$\&$ the world
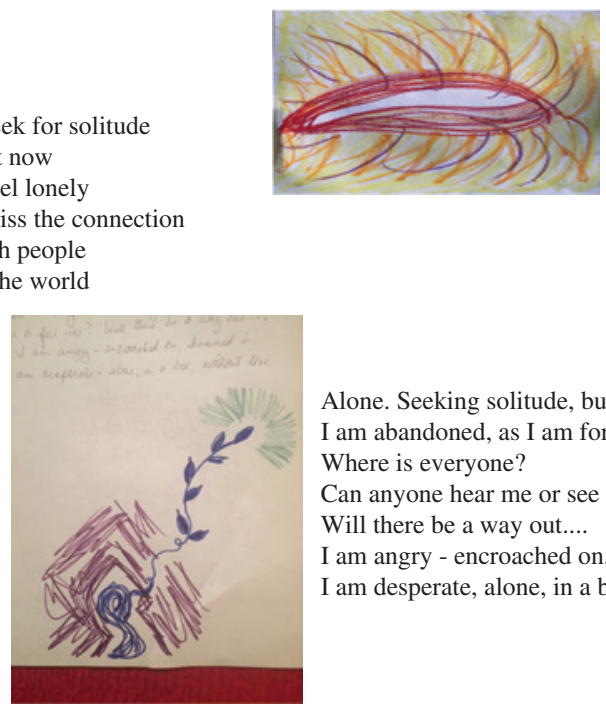

I wanted to have space for hope, resiliency, strength, and safety. Feelings we want for each other.

Alone. Seeking solitude, but finding emptiness.

I am abandoned, as I am forced to abandon.

Where is everyone?

Can anyone hear me or see me or feel me?

Will there be a way out....

I am angry - encroached on, hemmed in.

I am desperate, alone, in a box, without love.

FIGURE $1 \mid$ Art and poetry responses to the story of the change from peace seeking to isolation. 
starts to change. Because of It the world takes on a new appearance. It creates the stars, the moon, the earth, mountains, rivers, using Its wonderful painting pens, to create little by little. It is so creative! It creates everything around it. Then It starts to create a bunch of small creatures. They can breathe, fly, and run. They are free. They are looking for beauty. They are looking for strength. They are not satisfied with what they have. They won't stop until they find. (The dancer stopped here).

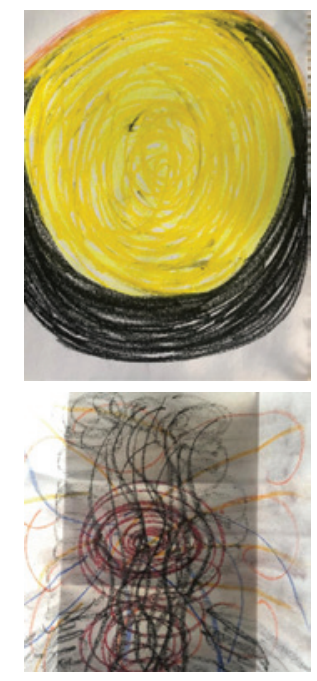

The image is of the sun and moon.

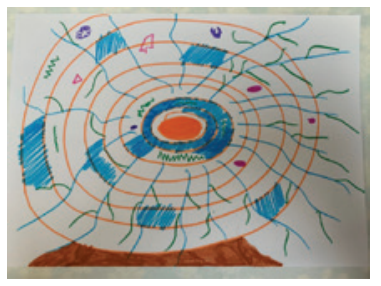

I feel the power of nature.

I feel more rooted.

I appreciate the power of life.
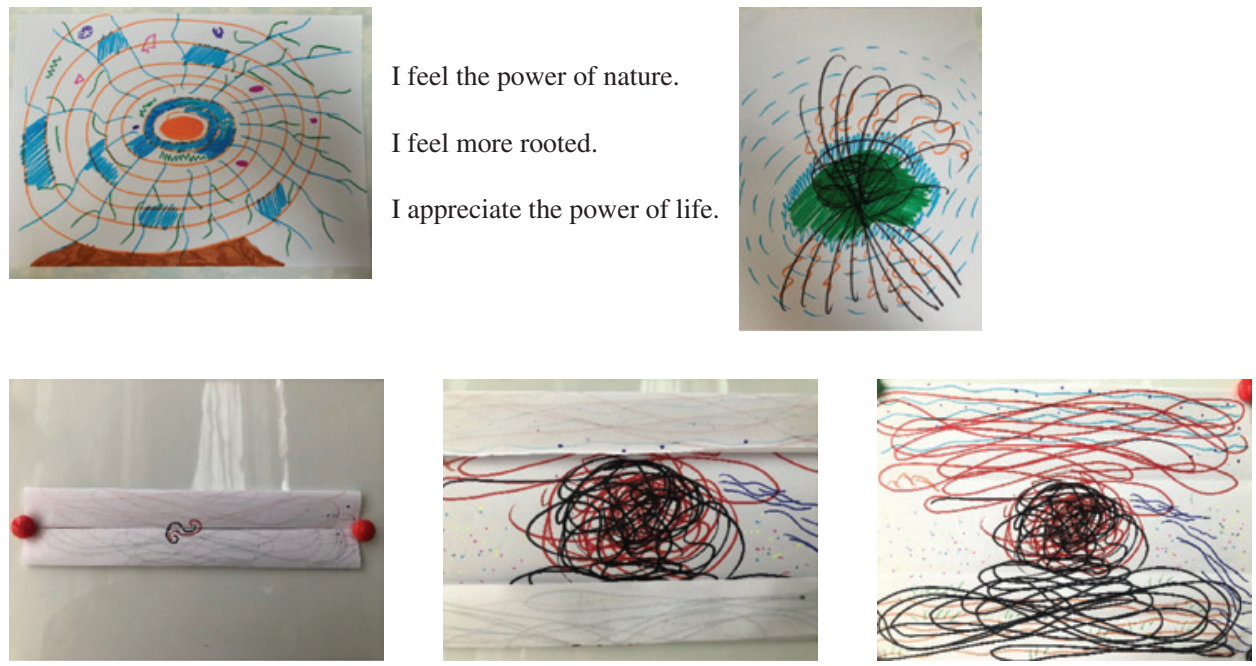

The Tao breaks giving birth to one. One gives birth to two. Two gives birth to three. Three gives birth to all things.

FIGURE 2 | (continued) 


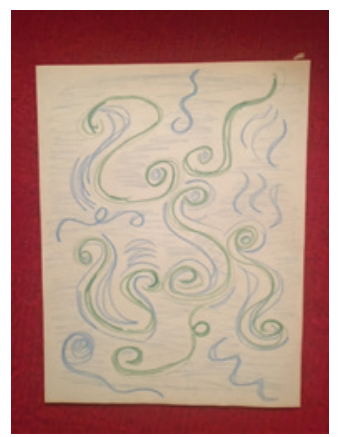

She is all the power

She is the wind and the rain

She is the sun and the gentle breeze

She is Kali The destroyer

She is the mother The creator

She will have mercy

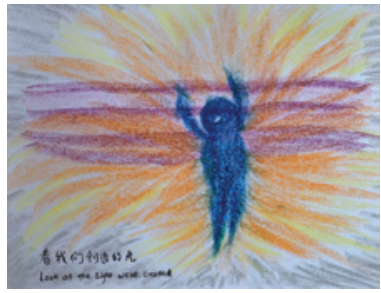

Look at the light

I have created.

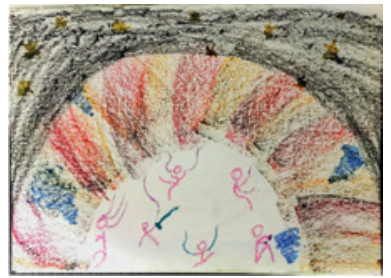

Darkens and stars. Typhoon. Horrible Tornados also bring power. Here are the little dare devils interacting with power. Transforming power into their own use. They are training themselves. They live with nature and create space for themselves to interact with nature.

FIGURE 2 | Art and poetic responses to both fairy tales.

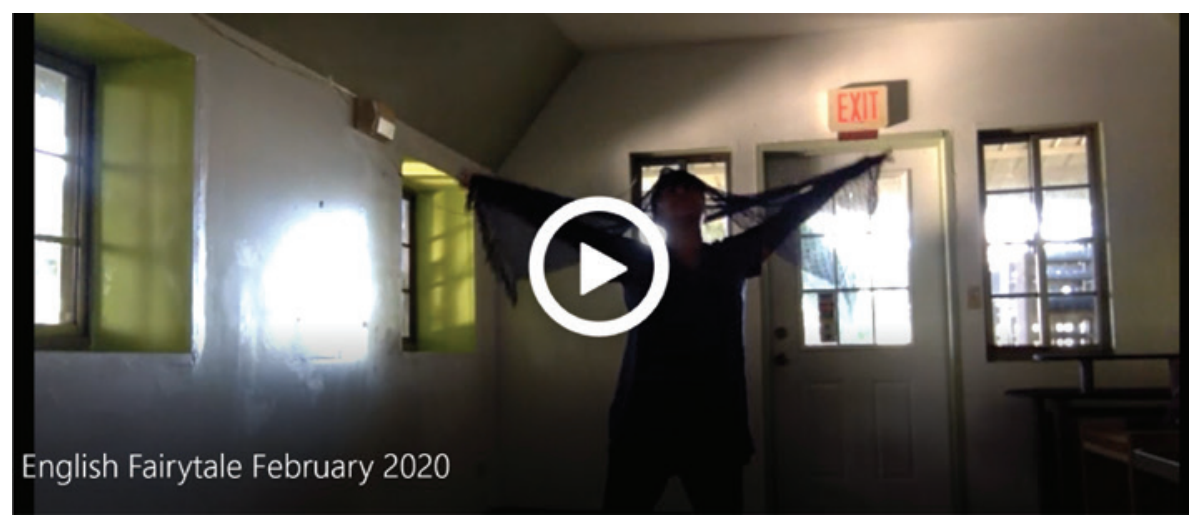

VIDEO 1 | The English Fairy Tale (https://vimeo.com/397387161).

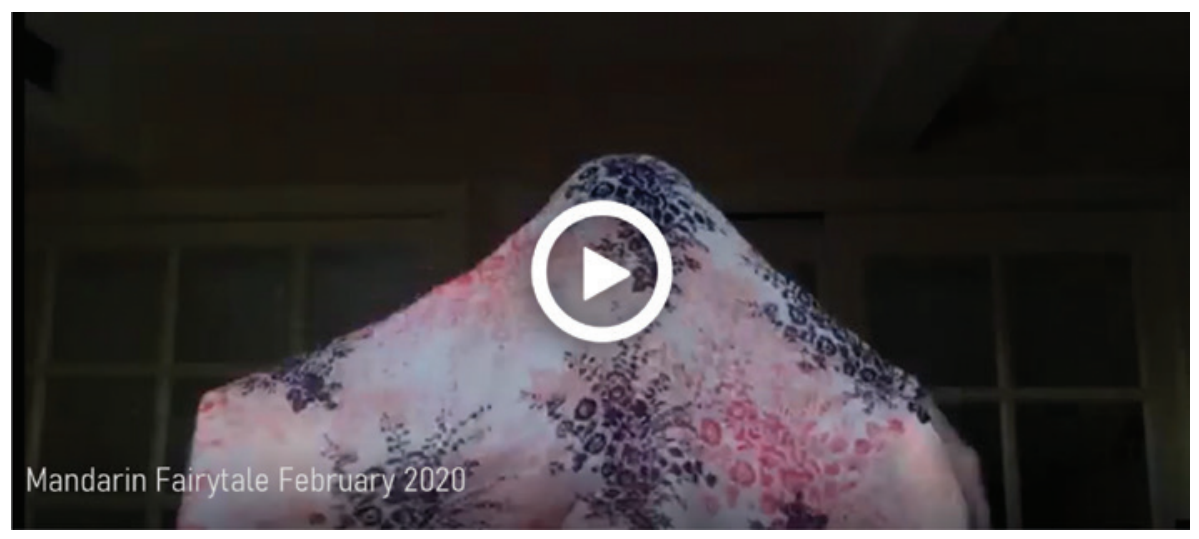

VIDEO 2 | The Mandarin Fairy Tale (https://vimeo.com/397387628). 


\section{Discussions after the Improvisations}

The group shared with each other after the arts and poetry presentations. The general theme of these expressions was that the sharing of creativity was a very positive experience, and it had generated a sense of connection. One woman noted that she had not known others from so far away before the session and yet the shared creativity had brought her to feeling very connected to the others in the present moment despite the fear and unknown related to the unusual and extreme time of crisis. Another woman said she felt calm, more grounded, and an appreciation for others despite the actual isolation of the circumstances. Yet another woman reported that she did not have words to describe her experience of the positive power of being together in the active spontaneous movement and creativity together. For her, the collaborations had created a nonverbal experience of being connected. This experience meant a lot.

The conductor then offered a summary of the session. "It seems that duality and nature have been running through our stories. One of the first images was about being close and far away at the same time. In the power of tragic times, there also is life and creativity. We are a somehow a part. The reach is profound."

\section{Reflections}

We began the session as mostly new to each other in many ways with the goal to develop a way to communicate even though we live in very different parts of the world. The health crisis was generating public conversations that were not including people in other countries as individuals with unique experiences. Such conversations were often creating more international tensions during a time of high human suffering. We were hoping to find a way to reach each other across the barriers of the fear of this common unfolding worldwide tragedy to develop conversations that were authentic for us. We also had the hope that the metaphors we developed might help to illuminate an emotional tone that others could sense in themselves.

The initial images presented from those in the middle of the emerging crisis included the subjective experience of isolation and mistrust. As we danced these images, a sense of empathy developed, which led to expressions of sadness and fear of the unknown. As we were able to create more elaborate metaphors in collaboration, strong positive feelings related to the connections and co-creativity emerged. The images we developed also had a reference to the presence of extensive destructiveness and a growth of powerful forces of the crisis. Such imagery not only reflected an actual physical virus but suggested emotional and a nonverbal tension among people from different parts of the world. However, the improvisation also led to a surprising expression of the positive power of creativity. The themes included nature and spirituality, particularly, as we confronted isolation. Often, these images contained both the positive aspects of connection alongside a sense of desperation. These metaphors served as an antidote, at least emotionally during our event. Since our session, a worldwide seeking of positive connections within and among communities is certainly emerging. This surge appears to match the emotional tone of our imagery. 
During the writing of this article, the health crisis and human toll have continued to spread through the world. There are now several online efforts designed to reach out to communities that are experiencing various levels of isolation and shut downs. At the same time, public conversation has also increased tension between countries and cultures. Our images and metaphors appear to capture, if not anticipate, these international dialogues. Our dialogue does not offer any political or international comment or answers. However, these metaphors do point to the power of collaborative creative expression across the borders of country and culture to introduce positive connection and understanding, particularly a nonverbal empathy, among people in times of immense tragedy. Our multimodal metaphors also offer a view of the some of the physically felt, visual, and poetic qualities of these possible new connections.

The women from China created artwork and video material in response to this meeting shortly after it ended (Figure 3). One of the images is shown below, and another video is available (https://youtu.be/fF44S8hIOsk). These images offer active metaphors of what some of the possible nonverbal experiences of the positive outcomes of an outreach between and within communities can feel like.

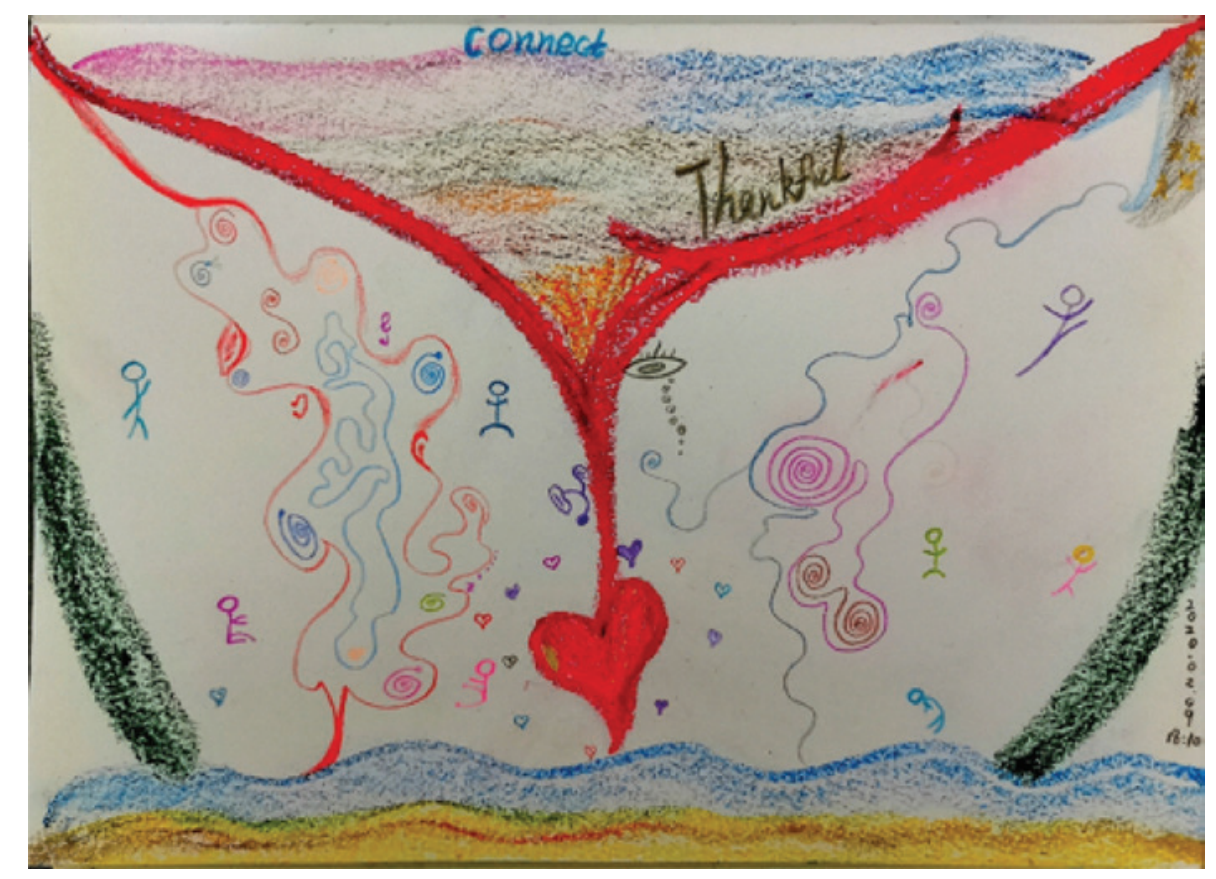

FIGURE 3 | Response to the online meeting completed shortly after the closing.

\section{Future Projects}

This creative arts collaboration across the globe in response to the spread of the coronavirus has connected us despite being confined to our own parts of the world. Moving, creating art and fairy tales, and reflecting together connected us to our 
creativity and to others beyond our immediate reach. Continued communications and care of one another after the initial meeting assured us that news and responses from our political leaders do not represent the bonds that people can have and create among ourselves.

This initial session occurred relatively early in the global crisis. We have agreed that we will meet again in the future to continue collaboration, as we expect there will changes within the emotional tone as more of the international community becomes impacted. We expect that our metaphors will be influenced. This collaboration has also grown to include other CATs in Europe and other creative forms such as the sand tray. As the coronavirus continues to spread to other parts of the world, this kind of creative dialogue can be a way to connect with one another across the globe in a way that is creative and embodied. Such collaborations might be able to help within and among communities in this time of unique isolations and apprehension.

After this event, some members of this group were able to join with Italian colleagues. Although the imagery was somewhat different, the general theme again reflected a shared strong positive experience that emerged from joining together in a creative collaboration. These images related to connection also contained reflections of confusion, disorientation, and a sense of dread within the same metaphors.

One of the CATs from China reported that she was able to develop a similar ZOOM session with a professional group she is consulting for. She reported that her group members were still in the actual isolation of the quarantine. She was able to facilitate collaborative movement, art, and storytelling. These expressions again contributed to positive experiences for those in her group (Tingting, personal communication, March 9,2020 ). We are planning future sessions to continue this work and hope to include CATs from Europe, China, and the United States.

\section{About the Authors}

Steve Harvey, PhD, BC-DMT, RPT/S, RDT is currently an adjunct faculty member at the University of Guam. He and his wife Connor Kelly are leading an ongoing arts-based inquiry addressing the emotional communication of tragedy among different countries.

E. Connor Kelly, MA, BC-DMT, LPC, DTAA (Prof DMT) is currently a Professional Lecturer in the Dance/Movement Therapy program at the University of Auckland, New Zealand. She supervises and mentors DMTs and students in Australasia.

Joan Wittig, MS, BC-DMT, LCAT is the co-founder of the Graduate Dance/Movement Therapy Program at Pratt Institute in New York City. She is the Program Director for the first dance/movement therapy training program in China, Inspirees International.

Alethea Bordallo, MA, in counselling from the University of Guam. She is now applying Creative Arts Therapy in her work on Guam.

Si Wang, MS, R-DMT, is currently the program manager for Inspirees Institute's Creative Arts Education and Therapy online program. 
Xiaoxi Peng, CMA, is associate professor in dance department of Chongqing University, who teaches dance history and choreography. She is also a doctoral candidate at Chinese Academy of Arts, specializing in research of images of ancient Chinese music and dance.

Tingting Song is a translator in Creative Arts and Somatics, and a national second-level psychological counselor. She has been training in dance/movement therapy, Laban/ Bartenieff Movement Studies, and Creative Movement, Garcia-Plevin Method.

$\mathrm{Xia} \mathrm{Li}$ is a full-time psychologist in China. She has 5 years of experience in clinical nursing prior to becoming a psychologist. Li's psychological counseling orientation is psychodynamic and DMT.

\section{References}

Harvey, S. A., \& Kelly, E. C. (2016). Arts based enquiry: Integrating narrative within movement. DTAA Journal, Moving On, 13(3/4), 2-9.

Harvey, S. A., \& Kelly, E. C. (2017a). A look at the journey score in physical storytelling. DTAA Journal, Moving On, 12(1/2), 3-10.

Harvey, S. A., \& Kelly, E. C. (2017b, December 9). “21. Physical storytelling.” Mind your body: A dance therapy perspective." Retrieved on Dec. 9, 2017 from www.mindyourbodydmt.com/21-physicalstorytelling

Harvey, S. A., Zhou, T., Kelly, E. C., \& Wittig, J. (2018). Physical conversations between the east and west: An arts-based inquiry into the cross-cultural emotional climate during a time of political tensions. Creative Arts in Education and Therapy, 4(1), 1-20.

Wang, S. (2020). One month dance challenge-Will you \#DanceForWuhan? Retrieved on March 31, 2020 from https://www.youtube.com/watch?v=9wgIGk9wZng

Wang, I., \& Green, D. (2017). Stitching east and west. Creative Arts in Education and Therapy, 3(1), $26-43$. 